\title{
суицидология
}

УДК 616.89-008.441.44:314.14:341.321.1(470.318)|40|

Для цитирования: Носова Е.С., Жуков И.В., Радулов С.П. Ретроспективный анализ динамики суицидальной смертности в Калужской области за 16-летний период. Сибирский вестник психиатрии и наркологии. 2020; 1 (106): 56-66. https://doi.org/10.26617/1810-3111-2020-1(106)-56-66

\section{Ретроспективный анализ динамики суицидальной смертности в Калужской области за 16-летний период}

\author{
Носова Е.С., Жуков И.В., Радулов С.П.
}

Калужская областная психиатрическая больница им. А.Е. Лифшиияа

Россия, 248009, Калуга, ул. Маяковского, 55

\section{PEЗЮME}

Согласно данным ВОЗ в 2016 г. Россия заняла третье место в мире по уровню самоубийств с общим стандартизованным по возрасту показателем 26,5 на 100 тыс. населения. Анализ суицидальной смертности на уровне субъектов Федерации - первый шаг в составлении общего представления об эпидемиологии самоубийств, рационален с учётом культурных, религиозных и этнических особенностей населения исследуемых территорий. Цель: изучить закономерности смертности от суицидов на региональном уровне, выявить «горячие точки» на карте региона и группы риска для первоочередных интервенций. Материалы и методы: проведён ретроспективный анализ смертности от самоубийств в Калужской области с 2003 по 2018 г. Показатели рассчитаны с учётом гендерных, возрастных различий и места жительства. Определены тренд и долгосрочный прогноз с применением линейного регрессионного анализа. Результаты: за исследуемый период суицидальная смертность в целом по региону демонстрирует положительную динамику со снижением коэффициентов суицидальной смертности (КСС) за период с 2003 по 2018 г. с 30,14 до 11,67 на 100 тыс. населения $\left(\mathrm{R}^{2}=0,9206\right.$; Fфакт $>$ Fтабл, $\left.\alpha=0,05\right)$, более выраженную у мужчин (с 54,15 до 20,31 на 100 тыс. населения, $\mathrm{R}^{2}=0,9265$; Fфакт $>$ Fтабл, $\alpha=0,05$ ) в сравнении с женщинами (с 9,96 до 4,24 на 100 тыс. населения, $\mathrm{R}^{2}=0,7177$; Fфакт $>\mathrm{F}$ табл, $\left.\alpha=0,05\right)$. C помощью линейной регрессии для всех указанных групп на период 2019-2022 гг. определяется положительный прогноз по дальнейшему снижению уровней КСС. Регрессионный анализ выделяет возрастные когорты со статистически значимым прогнозом по дальнейшему снижению показателей КСС на трехлетний период: лица 25-29, 30-34, 50-54 и 55-59 лет и когорта лиц трудоспособного возраста $\left(\mathrm{R}^{2}>0,6\right.$; Fфакт $>$ Fтабл, $\left.\alpha=0,05\right)$. Выводы: группа риска формируется за счёт мужчин трудоспособного возраста и старше 65 лет, а также женщин старше 85 лет. Рост самоубийств в когорте лиц старше 85 -летнего возраста на 45\% от исходных показателей в 2003 г. заслуживает пристального внимания и дальнейшего изучения.

Ключевые слова: суицидальная смертность, динамические ряды, линейная регрессия, кризисная помощь, Калужская область.

Живые знают, что умрут, а мертвые ничего не знают, и уже нет им воздаяния, потому что и память о них предана забвению, и любовь их и ненависть их и ревность их уже исчезли, и нет им более части во веки ни в чем, что делается под солнцем.

\section{ВВЕДЕНИЕ}

Экклезиаст, 9:5-9:6

В 2019 г. темой для Всемирного дня психического здоровья была выбрана профилактика суицидов, что нашло отражение в однодневной акции «40 секунд действия». Предложено повысить информированность населения по проблеме самоубийств, затратив 40 секунд на инициацию беседы с окружающими: близкими, коллегами, друзьями. Оказывая им поддержку или запросив её для себя, каждый, независимо от своего социального положения, привлекает внимание к вопросам самоубийства в своей среде, охватывая всё большее количество людей [1]. Легко проводится параллель с основ- ным посылом Национальной стратегии по профилактике суицидов в Японии, своего рода философией «создания общества, в котором никто не посягает на свою жизнь» и каждый третий распознаёт знаки суицидального поведения [2]. Актуальность таких действий обусловлена общемировыми потерями в результате самоубийств - ежегодно более 800000 смертей и одна жертва ежеминутно [3].

В 2018 г. количество умерших от всех причин смерти в России составило 1828910 чел., из них более миллиона смертей обусловлено болезнями системы кровообращения (856 127) и новообразованиями (297 996). Суициды составляют менее $1 \%$ от общего числа, но в случае с самоубийствами из официально зарегистрированных 18206 смертей часть, безусловно, предотвратима [4]. 
Динамика смертности от суицидов в РФ за последние десятилетия характеризуется снижением показателей от 26,5 в 1990 г. до 12,4 в 2018 г. на 100 тыс. населения. При более детальном анализе в 90-е гг. и начале 2000 -х гг. регистрируются два пика суицидальной смертности, предположительно обусловленные периодами радикальных социальных преобразований и экономической рецессии $[5,6,7]$. Впечатляет диапазон показателей коэффициентов суицидальной смертности (КСС) на региональном уровне. Так, в 2018 г. разница между КСС в регионах составила более 200 раз (от 44,4 на 100 тыс. населения в Чукотском автономном округе до 0,2 на 100 тыс. населения в Республике Ингушетия) [8]. С большей степенью вероятности это обусловлено многонациональным составом России, её культурноэтническими и религиозными особенностями, что лишь подчёркивает необходимость изучения суицидов на местном уровне.

Таким образом, первым шагом на пути к развитию региональной системы кризисной помощи является оценка ситуации на месте: ретроспективный и проспективный анализ статистической информации об исследуемом явлении, планирование интервенций на основе полученных данных с учётом локальных условий и потенциальных возможностей.

\section{ЦЕЛЬ ИССЛЕДОВАНИЯ}

Изучить закономерности смертности от суицидов на региональном уровне, выявить «горячие точки» на карте региона и группы риска для первоочередных интервенций.

\section{МАТЕРИАЛЫ И МЕТОДЫ}

Исследованы данные ТОФС ГС по Калужской области «Калугастат», Федеральной службы государственной статистики (Росстат) по суицидальной смертности населения Калужской области (КО) за период с 2003 г. по 2018 г. На основании абсолютных показателей (число самоубийств) и среднегодовой численности населения КО рассчитаны коэффициенты суицидальной смертности для региона с учётом гендерных и возрастных различий, а также места жительства суицидентов. Для каждой группы построены динамические ряды, как для абсолютных чисел, так и для относительных. Для общих региональных показателей, а также мужского и женского, городского и сельского населения и ряда возрастных когорт проведен дополнительный углубленный линейный регрессионный анализ динамики КСС с выделением тренда и составлен прогноз на 2019-2022 гг.
Регрессионный анализ данных проводился при помощи надстройки «Анализ данных» в Microsoft Excel (режим «Регрессия»). Статистическая значимость уравнения проверена с помощью коэффициента детерминации и критерия Фишера при уровне значимости $\alpha=0,05$.

\section{РЕЗУЛЬТАТЫ}

\section{Калужская область в зеркале демографии}

Калужская область - субъект Российской Федерации в составе Центрального федерального округа, расположенный в Европейской части России. Административным центром Калужской области является город Калуга. Территориально на 1 января 2017 г. состоит из 24 муниципальных районов, 2 городских округов (ГО), 26 городских и 252 сельских поселений. Общая численность населения 1014570 чел. (76\% городского против $24 \%$ сельского) [9, 10 , $11,12]$. Доля мужского населения в общей численности $-46,2 \%$, женского - 53,8\% [9]. Ожидаемая продолжительность жизни при рождении в 2016 г. составляет 71,18 года: у мужчин 65,46 года, у женщин 76,87 года [13].

Мужская смертность с 1990 по 2016 г. практически во всех возрастных группах превышает женскую среди городского и сельского населения. В структуре смертности традиционно лидируют болезни системы крови, новообразования и внешние причины смерти. Однако, согласно данным «Калугастат» о смертности трудоспособного населения в Калужской области за период с 2012 по 2016 г., абсолютное число умерших в трудоспособном возрасте (ТCB) от внешних причин смерти в разные годы опережает и превосходит число умерших от болезней системы крови в 23 районах области [13].

Среди внешних причин смерти (ВПС) внимание традиционно акцентируется на 4 наиболее распространённых: случайных отравлениях алкоголем, транспортных несчастных случаях, убийствах и суицидах. В 2000 г. суициды лидировали среди ВПС с показателем 39,5 на 100 тыс. населения, за ними следовали случайные отравления алкоголем $(37,2)$, все виды транспортных несчастных случаев $(29,2)$ и убийства $(25,3)$. В 2016 г. самоубийства уже занимают третью позицию (14,8 на 100 тыс. населения) после транспортных несчастных случаев $(20,2)$ и случайных отравлений алкоголем $(16,1)$. Процент трудоспособного населения, погибшего от основных 4 причин смерти в группе ВПС, представлен в таблице 1 и демонстрирует, что во всех этих группах более половины умерших - лица трудоспособного возраста [14]. 
Т а б л и ц а 1. Удельный вес лиц трудоспособного возраста, умерших от ВПС в 2016 г.

\begin{tabular}{|l|c|c|c|}
\hline \multicolumn{1}{|c|}{ Причина смерти } & Всего, кол-во случаев & ТСВ, кол-во случаев & ТСВ от общего числа, \% \\
\hline Транспортные несчастные случаи & 204 & 143 & $\mathbf{7 0 , 1}$ \\
\hline Случайные отравления алкоголем & 163 & 126 & $\mathbf{7 7 , 3}$ \\
\hline Самоубийства & 150 & 104 & $\mathbf{6 9 , 3}$ \\
\hline Убийства & 67 & 53 & $\mathbf{7 9 , 1}$ \\
\hline Всего внешних причин смерти & 1215 & 800 & $\mathbf{6 5 , 8}$ \\
\hline
\end{tabular}

Суицидальная смертность в Калужской области в 2003-2018 z2.

По данным Федеральной службы государственной статистики (Росстат), в 2018 г. Калужская область занимает 8-е место в Центральном федеральном округе по величине КСС - 11,7 на 100 тыс. населения [5].

За период с 2003 по 2018 г. выявляется чёткий тренд к снижению показателей в 2,5 раза - c 30,14 до 11,67 на 100 тыс. населения $\left(\mathrm{R}^{2}=0,9206 ;\right.$ Fфакт $>$ Fтабл, $\left.\alpha=0,05\right)$ (рис. 1). Так, в 2018 г. в результате суицидов в области погибло на 200 человек меньше, т.е. на $63 \%$ по сравнению с 2003 г. С помощью регрессионного анализа выявляется статистически значимая тенденция к дальнейшему снижению КСС на период 2019-2022 гг.

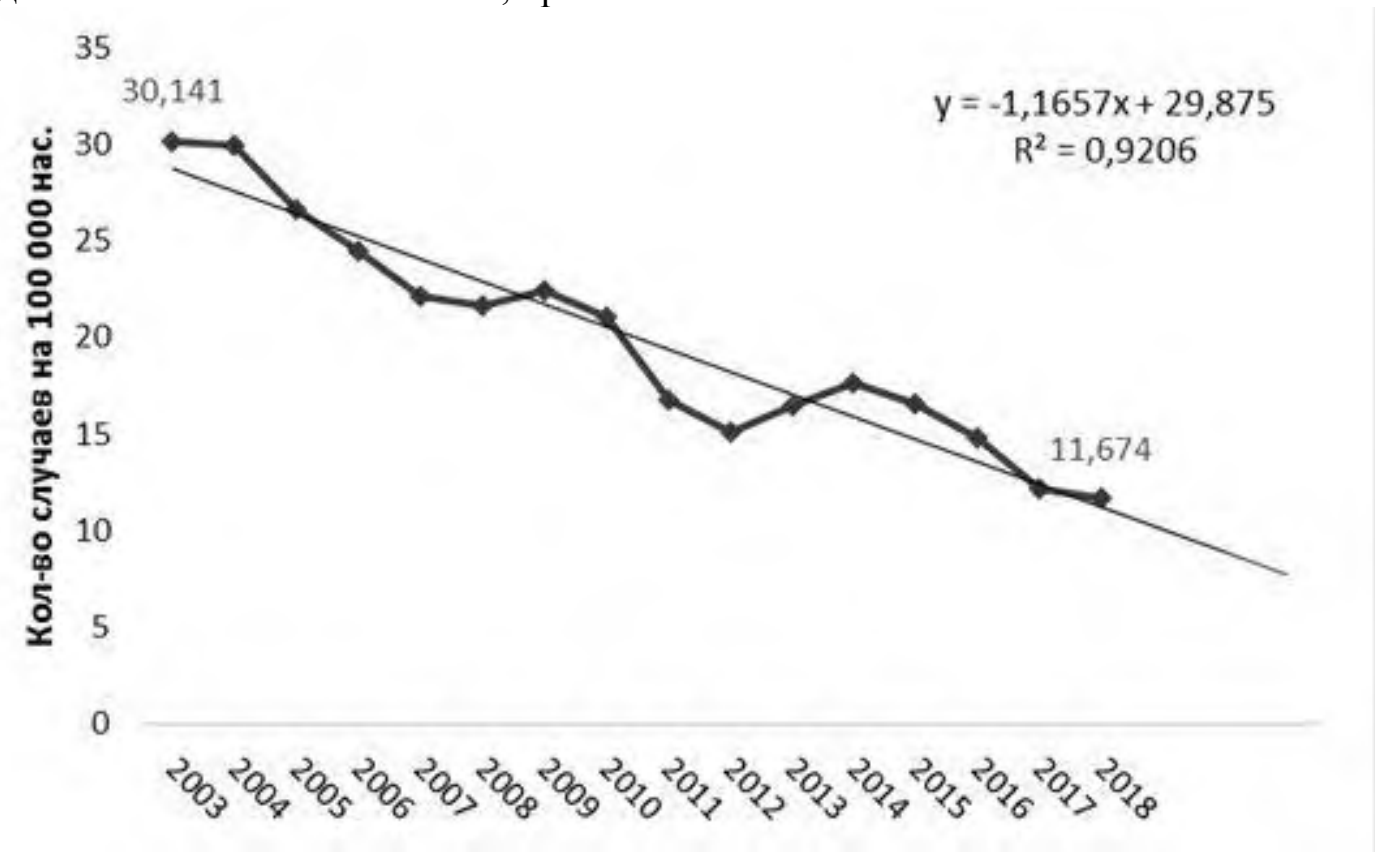

\section{Р и с у н о к 1. Динамика показателей суицидальной смертности в Калужской области с 2003 по 2018 г. и линейный прогноз на 2019-2022 гг., кол-во случаев на 100 тыс. населения}

Тренд к снижению прерывался ростом показателей в некоторые годы: 2009 г., 2013 г. и 2014 г., что требует дополнительного изучения и выявления причинно-следственных связей с социально-экономическими событиями.

Максимальное снижение показателей (как абсолютных, так и относительных) отмечалось в 2011 г. - более $20 \%$ от предыдущего периода (на $34,29 \%$ у женщин и на $17,98 \%$ у мужчин). Согласно подходу ВО3, региональный уровень суицидов в 2018 г. определяется как средний, в то время как в начале исследуемого периода он может быть обозначен как сверхвысокий. Так, 19 из 26 районов в 2003 г. продемонстри- ровали сверхвысокие показатели - от 30,35 на 100 тыс. населения в Людиновском районе до 77,08 в Барятинском. И лишь в ГО Обнинск отмечены низкие цифры. В 2018 г. картина приобретает иные черты: в группе со сверхвысокими показателями, напротив, оказываются лишь 3 района из 26, низкие показатели демонстрируют уже большинство районов - 11 .

Практически дублируют данное распределение КСС городского и сельского населения.

Согласно анализу динамических рядов показатель наглядности $(2018$ г./2003 г.) в 23 районах региона менее $100 \%$, при этом в 6 из них он равен нулю, что говорит не только о сниже- 
нии показателей, но и о полном отсутствии явления в конце исследуемого периода на определённой территории области. Тем не менее в Дзержинском, Спас-Деменском районах, ГО Обнинск КСС в 2018 г. превышают таковые значения в 2003 г. Так, в ГО Обнинск показатель наглядности в 2018 г. равен 331,99\% по отношению к исходной точке динамического ряда. В то же время такой рост обусловлен ростом абсолютных чисел на 8 самоубийств в 2018 г., что резко контрастирует между абсолютными и относительными показателями и требует от исследователей с осторожностью относиться к эпидемиологической значимости анализируемых данных.

В Дзержинском районе КСС в 2018 г. выше таковых значений в 2003 г. (20,80 на 100 тыс. населения против 19,69), но в то же время обнаружена обратная динамика для абсолютных чисел: 11 суицидов в 2018 г. и 12 в 2003 г. Рост относительных показателей в Спас-Деменском районе в первую очередь обусловлен убылью населения, поскольку число суицидов остаётся прежним - 3 за год, как в 2003 г., так и в 2018 г.

Отдельно следует обозначить районы, в которых отмечается снижение абсолютных и относительных показателей более чем на 70\%: Барятинский, Боровский, Жиздринский, Жуковский, Износковский, Кировский, Людиновский, Медынский, Мосальский, Мещовский, Перемышльский, Сухиничский, Ферзиковский, Хвастовичский.

Обращает на себя внимание разрыв показателей в сельской местности и городе в исходный год (рис. 2). В 2003 г. суициды на селе превышали таковые в городе в 2 раза, при этом в абсолютных числах показатели на селе были ниже на $32,3 \%$. Уровни суицидов за 16-летний период в городе снизились на 55\%, но ещё более на селе - около $70 \%$.

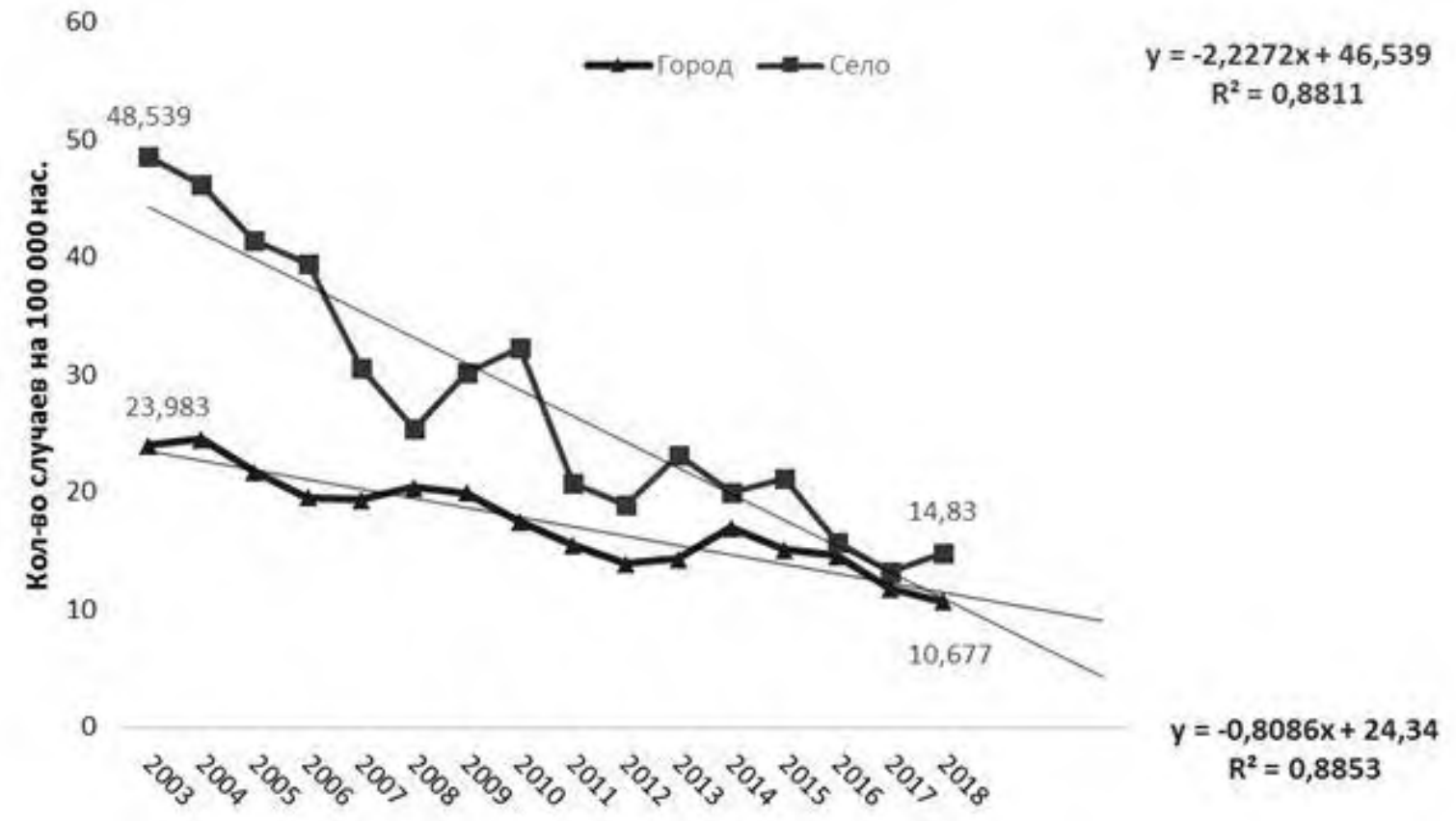

Р и с у н о к 2. Динамика показателей суицидальной смертности городского и сельского населения Калужской области с 2003 по 2018 г. и линейный прогноз на 2019-2022 гг., кол-во случаев на 100 тыс. населения

При этом в начале изучаемого периода сельские коэффициенты можно было определить как сверхвысокие (48,54 на 100 тыс. населения), а в городе как высокие $(23,98)$. К 2018 г. в обеих группах они достигают средних величин. В 2016 г. произошло практически полное уравнивание показателей в городе и на селе, но с 2017 г. уровни суицидов на селе вновь начинают расти. Тем не менее линейный регрессионный анализ позволяет предположить сохранение положительной динамики в КСС как в городе, так и на селе на ближайшие 3 года $\left(\mathrm{R}^{2}>0,8 ;\right.$ Fфакт $>$ Fтабл, $\left.\alpha=0,05\right)$.

Гендерные различия суицидальной смертности в Калужсккой области

В обеих гендерных группах прослеживается аналогичный тренд с более резким снижением показателей у мужчин (с 54,15 до 20,31 на 100 тыс. населения, $\mathrm{R}^{2}=0,9265 ; \quad$ Fфакт $>$ Fтабл, $\alpha=0,05$ ) в сравнении с женщинами (с 9,96 до 4,24 на 100 тыс. населения, $\mathrm{R}^{2}=0,7177$; Fфакт $>$ Fтабл, $\alpha=0,05$ ) (рис. 3). 


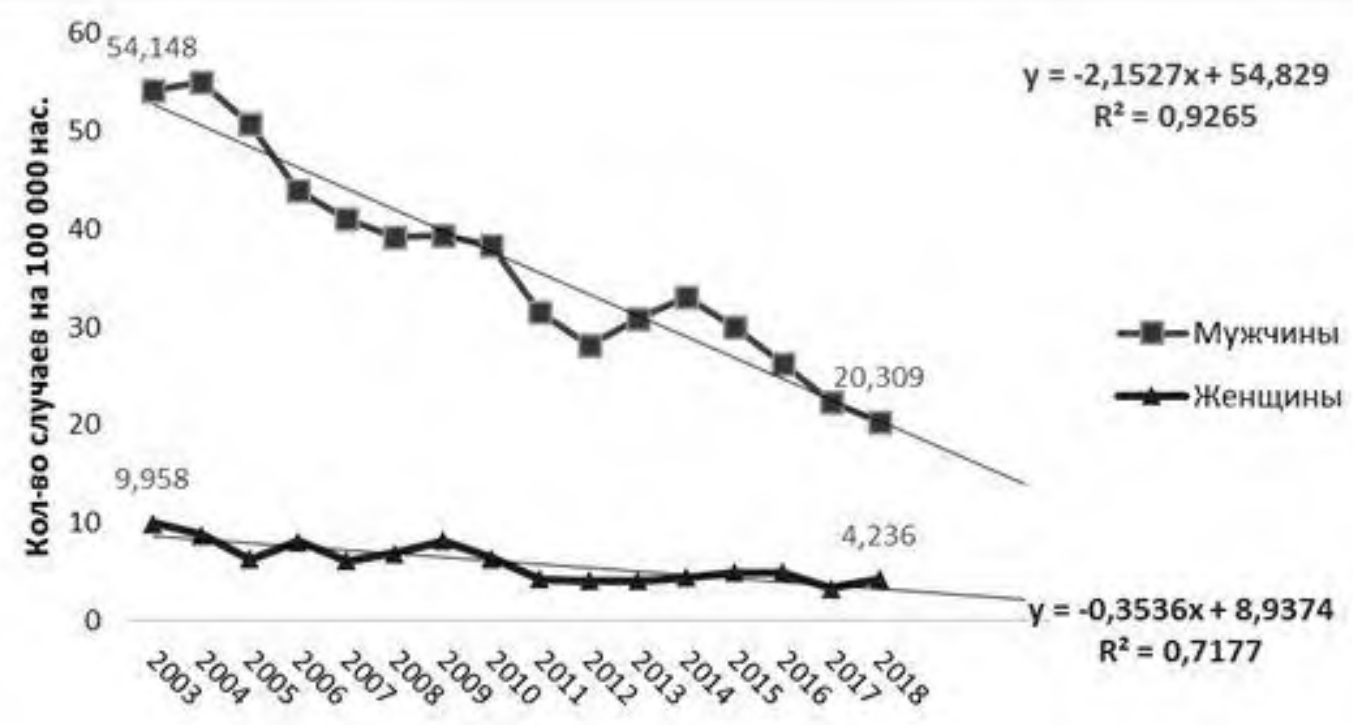

Р и с у н о к 3. Гендерные различия показателей суицидальной смертности в Калужской области с 2003 по 2018 г. и линейный прогноз на 2019-2022 гг., кол-во случаев на 100 тыс. населения

Показатель КСС у мужчин изменяется от сверхвысокого в 2003 г. до высокого спустя 16 лет, а у женщин остаётся на низком уровне. Соотношение КСС мужчин и женщин в 2003 г. равно 5,44:1, а в 2018 г. незначительно снижается - до 4,79:1.

Максимальное снижение КСС у мужчин в регионе отмечалось в 2011 г. - на 17,85\% в сравнении с КСС за предшествующий год. Максимальный рост зафиксирован в 2013 г. на $10,12 \%$ за год. У женщин наибольшая положительная динамика зарегистрирована в 2011 г. и 2017 г.: снижение на 33,97\% и 33,33\% соответственно. «Худшие» периоды в 2006 г. и 2018 г. отмечены ростом показателей на $29,05 \%$ и $28,25 \%$ соответственно.

Необходимо отметить сверхвысокие показатели суицидальной смертности в контингенте мужчин - жителей сельской местности, которые в 2003 г. достигают драматичных цифр 90,52 на 100 тыс. населения, демонстрируя выраженное снижение более чем на $70 \%$ в 2018 г. - 23,87 на 100 тыс. населения. В городе показатели у мужчин также отталкиваются от сверхвысоких значений в 2003 г. (что в 2 раза меньше в сравнении с сельскими), но снижаются до средних (19,12 на 100 тыс. населения) в 2018 г. Показатели в женской когорте традиционно ниже мужских во всех группах населения, в 2018 г. с положительной динамикой они достигают низких значений согласно классификации ВО3 как в городе $(3,59$ на 100 тыс. населения), так и на селе $(6,38)$.
Анализируя гендерные различия КСС на уровне районов, можно выделить некоторую специфику. В $85 \%$ районов Калужской области в 2003 г. отмечались сверхвысокие уровни суицидальной смертности среди мужчин. Большая их часть продемонстрировала снижение КСС за исследуемый период. Тем не менее в 8 районах показатели мужской суицидальной смертности в 2018 г. по-прежнему выше 30 на 100 тыс. населения, К ним относятся Думиничский $(45,13), \quad$ Куйбышевский $(55,84)$, СпасДеменский $(60,96)$, Ульяновский $(61,46)$, Юхновский $(40,63)$, Бабынинский $(47,54)$, Дзержинский $(39,43)$ и Малоярославецкий $(43,88)$ районы. Такое же количество районов демонстрируют низкие показатели суицидов среди мужчин: в Барятинском, Жиздринском, Жуковском, Износковском, Людиновском, Медынском и Перемышльском районах в 2018 г. суицидов не зарегистрировано, в Боровском - 9,89 на 100 тыс. населения.

Что касается женских суицидов, в большей части районов как в начале, так и в конце исследуемого периода показатели КСС низкие. Более того, в 2018 г. сверхвысоких цифр не отмечено, а высокие показатели КСС (обусловленные единичными случаями суицидов) отмечаются в 4 районах: Тарусском, Думиничском, Куйбышевском и Спас-Деменском. Думиничский район как в 2003 г., так и в 2018 г. относится к группе с высокими показателями женской суицидальной смертности, которые перемежаются с полным отсутствием явления в течение ряда лет. 
Анализ динамики КСС в разных возрастных когортах жителей Калужской области

В 2003 г. среди всех возрастных когорт наиболее высокие показатели отмечаются в группе лиц 70-74 лет (51,68 на 100 тыс. населения), 55-59 лет $(50,75)$ и 40-44 лет $(48,49)$. Сверхвысокие показатели демонстрировали 10 возрастных когорт из 18: начиная с группы лиц
25-29 лет и вплоть до возрастного интервала 60-64 года уровень КСС выше 30 на 100 тыс. населения. В 2018 г. отмечается общее снижение показателей в большинстве возрастных групп. Только в одной возрастной когорте выявлены сверхвысокие уровни КСС: в группе лиц старше 85 лет в 2018 г. зафиксирован рост на 45\% по отношению к 2003 г. (рис. 4).

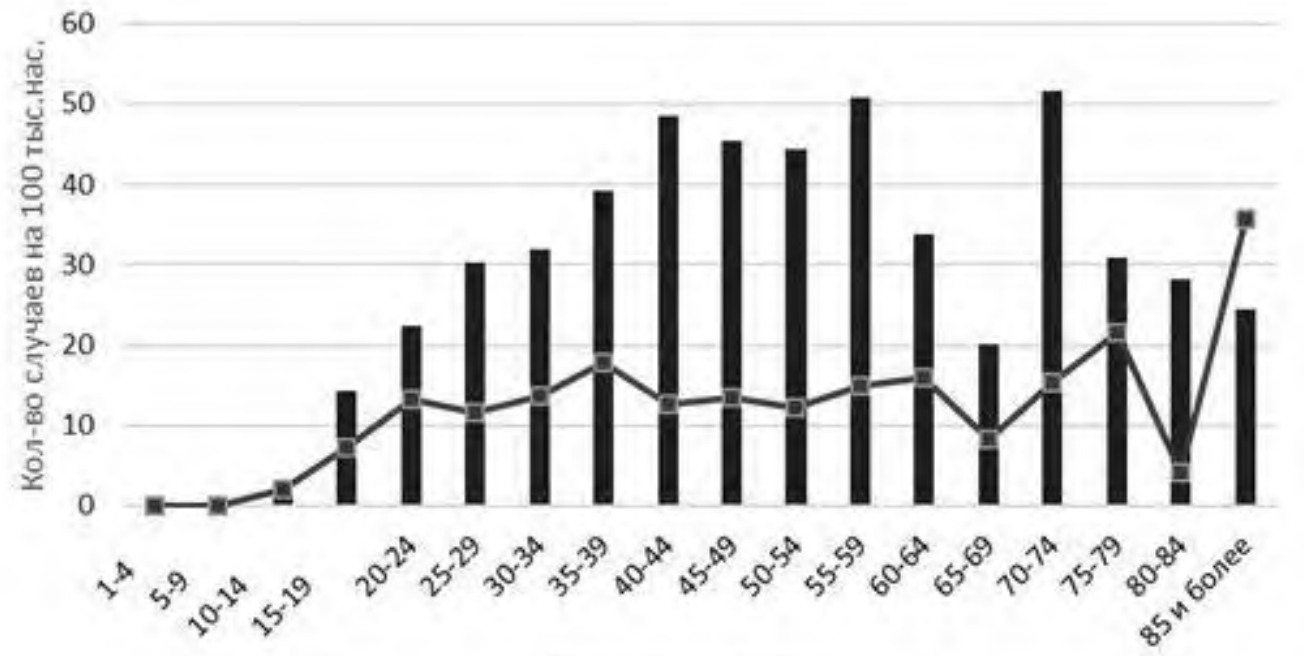

Возрастные когорты

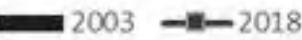

Р и с у н о к 4. Распределение показателей КСС в различных возрастных когортах населения Калужской области в 2003 г. и 2018 г., кол-во случаев на 100 тыс. населения

У мужчин в 2003 г. сверхвысокие показатели отмечаются начиная с возрастной когорты 20-24 лет и до 80-84 лет включительно, в то время как в 2018 г. - только в 4 возрастных группах: 60-64, 70-74, 75-79 и старше 85 лет. Вместе с тем, несмотря на положительную динамику в целом, в возрастном интервале 20-59 лет КСС остаются высокими. У женщин в начале исследуемого периода КСС выше 30 на 100 тыс. населения отмечались только в одной возрастной группе - 70-74 лет, в 2018 г. сверхвысоких КСС не зарегистрировано, высокие - в когорте лиц старше 85 лет.

Следует отметить, что в 11 возрастных интервалах КСС за 16-летний период снизились более чем на $50 \%$ от исходного уровня. Проведён анализ графиков динамики КСС за указанный период, выделено 5 возрастных когорт $\left(\mathrm{R}^{2} \geq 0,6\right)$. Среди них возрастные группы 25-29, $30-34,50-54$ и 55-59 лет и когорта ТСВ. В отношении указанных когорт проведён дополнительный регрессионный анализ и получена статистическая значимость с целью прогноза по дальнейшему снижению уровней КСС на период 2019-2022 гг. (Гфакт>Гтабл, $\alpha=0,05)$.

\section{ОБСУЖДЕНИЕ}

Впервые проведен углубленный анализ динамических рядов с изучением гендерных, возрастных, территориальных различий суицидальной смертности в КО. Основные тенденции, выявленные в ходе работы, созвучны с общероссийскими и являются типичными для других регионов европейской части России $[15,16,17]$. Так, по данным отечественных исследователей, смерти мужчин определяют 89\% потерь YLL (годы утраченной жизни из-за преждевременной смерти) в связи с суицидами, a большая часть социально-экономического бремени приходится на мужчин ТСВ [18]. Феномен объяснён более выраженными социальными стрессами в возрастной когорте, предполагающей интенсивное карьерное становление, а также рядом демографических проблем [19]. Вариабельность риска самоубийств в разные периоды жизни - закономерный индикатор взаимосвязи суицидов и социальноэкономического благополучия, что подчеркивает актуальность социальной интеграции в периоды резких изменений $[20,21]$. Традиционно уязвимой возрастной когортой является группа 
пожилых при синергии большого количества факторов риска суицида: отягощенность психической и сопутствующей соматической патологией, низкая стрессоустойчивость, социальная изоляция [22, 23, 24].

Дискутабельным остаётся вопрос точности данных официальной статистики. Ранее показано, что реальные уровни суицидов на порядок выше официально зарегистрированных, а ниша латентных суицидов формируется за счёт рубрики смерти от внешних причин с неопределёнными намерениями [17]. Улучшение качества данных возможно при усилении межведомственного взаимодействия: тренинги и образовательные программы для следователей и судебно-медицинских экспертов необходимы для оптимизации сбора информации о каждом случае неясной смерти, проведении психологической аутопсии и следующей за этим верификации диагноза суицида.

Сравнительный анализ суицидальной смертности в демографических группах целесообразно проводить с применением стандартизации и учётом естественного движения населения на данных территориях, что снизит погрешности в расчётах КСС. Это следует считать ограничением данного исследования и направлением для дальнейших разработок.

Перспективным является изучение корреляции показателей смертности с подушевым доходом и иными параметрами социальноэкономического благополучия городского и сельского населения. Чтобы объяснить колебания уровней суицидов, мы должны понимать специфику экономического и социального контекста региона в определённые временные периоды. Так, рост показателей, с большей вероятностью, связан с усилением финансовоэкономических стрессоров, в то время как тренд к снижению, наоборот, отражает благополучие изучаемой территории [21].

Однако с учетом того, что динамика суицидов вряд ли может быть объяснена с позиций воздействия лишь одного фактора, наиболее оптимальным является исследование влияний их комбинаций и особенно интеракций между ними. Поиск объяснений и дифференциация причин суицидального поведения находятся за пределами данной работы. Тем не менее стоит отметить, что перспективным с этих позиций нам представляется использование сетевого анализа как метода интегрированного биопсихосоциального подхода к суицидогенезу [25].

\section{ЗАКЛЮЧЕНИЕ}

Таким образом, на фоне снижения общих показателей смертности в Калужской области первая тройка основных классов причин смерти остаётся прежней и представлена болезнями системы крови, новообразованиями и внешними причинами смерти. Внутренняя структура группы ВПС изменилась за счёт снижения КСС и смещения суицидов на третью позицию после случайных отравлений алкоголем и всех видов транспортных несчастных случаев. Суицидальная смертность демонстрирует положительную динамику со снижением КСС за период с 2003 по 2018 г. с 30,14 до 11,67 на 100 тыс. населения $\left(\mathrm{R}^{2}=0,9206\right.$; Fфакт $>$ Fтабл, $\left.\alpha=0,05\right)$ в целом по региону, более выраженную у мужчин (c 54,15 до 20,31 на 100 тыс. населения, $\mathrm{R}^{2}=0,9265$; Fфакт $>$ Fтабл, $\left.\alpha=0,05\right)$ в сравнении с женщинами (с 9,96 до 4,24 на 100 тыс. населения, $\mathrm{R}^{2}=0,7177$; Fфакт $>$ Fтабл, $\left.\alpha=0,05\right)$. Аналогичный тренд выявлен у городских и сельских жителей. Заслуживает внимания уравнивание показателей в городе и на селе в 2016 г. при разнице более чем в 2 раза в исходной точке динамического ряда (2003 г.).

С помощью линейной регрессии для всех указанных групп на ближайшие 3 года определяется положительный прогноз по дальнейшему снижению уровней КСС. В районах с высокими коэффициентами суицидальной смертности уместен также и анализ общей смертности, особенно естественного движения населения на данной территории [26]. К числу таких можно отнести районы, в которых, несмотря на положительную динамику за исследуемый период, всё же отмечаются высокие и сверхвысокие показатели смертности от самоубийств: Бабынинский, Дзержинский, Малоярославецкий, Ульяновский, Юхновский, Думиничский, Куйбышевский, Спас-Деменский. Отдельное внимание следует уделить этим районам в связи с отмеченными в них сверхвысокими КСС у мужчин. Тем не менее сравнение между собой и выделение районов с контрастными КСС возможно лишь после проведения процедуры стандартизации показателей смертности.

Анализ КСС в возрастных когортах продемонстрировал снижение показателей смертности от самоубийств во всех возрастных интервалах, за исключением когорты лиц старше 85 лет, в которой наблюдается рост КСС на 45\% от исходного уровня в 2003 г. Линейная регрессия позволяет выделить возрастные когорты со статистически значимым прогнозом по даль- 
нейшему снижению показателей КСС на трехлетний период: 25-29, 30-34, 50-54 и 55-59 лет и когорта ТСВ $\left(\mathrm{R}^{2}>0,6\right.$; Fфакт $>$ Fтабл, $\left.\alpha=0,05\right)$. В группу риска входят мужчины трудоспособного возраста и старше 65 лет, а также женщины старше 85 лет. Рост КСС в когорте 85летних и старше на $45 \%$ от исходных показателей в 2003 г. заслуживает внимания и дальнейшего изучения.

\section{КОНФЛИКТ ИНТЕРЕСОВ}

Авторы заявляют об отсутствии явных и потенциальных конфликтов интересов в связи с публикацией данной статьи.

\section{ИСТОЧНИК ФИНАНСИРОВАНИЯ}

Авторы заявляют об отсутствии финансирования при проведении исследования.

\section{ЛИТЕРАТУРА}

1. Всемирная организация здравоохранения [Электронный ресурc]. URL: https://www.who.int/docs/defaultsource/mental-health/suicide/suicide-flyer-ru.pdf (дата обращения 13.10.2019)

2. The General Principles of Suicide Prevention Policy. Realizing a Society in Which No One Is Driven to Take Their Own Life - Cabinet Decision, $25^{\text {th }}$ July 2017. [Электронный peсурс]. URL: http://www.mindbank.info/item/6766 (дата обращения 15.11.2019)

3. Всемирная организация здравоохранения [Электронный pecypc]. URL: https://www.who.int/mental_health/suicide-

prevention/infographic/ru/ (дата обращения 07.12.2019)

4. Федеральная служба государственной статистики Росстат [Электронный ресурс]. URL: https://www.fedstat.ru/indicator/31620 (дата обращения 15.12.2019).

5. Федеральная служба государственной статистики Росстат [Электронный ресурс]. URL: https://www.fedstat.ru/indicator/31270 (дата обращения 01.12.2019).

6. Положий Б.С., Игумнов С.А., Ример 3. и др. Суициды в России и Европе / под ред. Б.С. Положего. М. : Медицинское информационное агентство, 2016: 209.

7. Гладышев М.В. Клинико-социальные аспекты распространенности суицидов в период радикальных преобразований в России (1990-2003 гг.): дис. ... к.м.н. М., 2006: 169.

8. Федеральная служба государственной статистики Росстат [Электронный ресурс]. URL: https://www.fedstat.ru/indicator/31270 (дата обращения 15.12.2019)

9. Росстат / ТОФС ГС по Калужской области (Калугастат). Муниципальные образования Калужской области в зеркале демографии. Статистический сборник. Калуга, 2017: 116.

10. Федеральная служба государственной статистики. Федеральное агентство по техническому регулированию и метрологии. Общероссийский классификатор территорий муниципальных об- разований ОК 33-2013. Т. 1. Центральный федеральный округ. М., 2013: 1499.

11. Официальный портал органов власти Калужской области [Электронный pecypc]. URL: https://admoblkaluga.ru/main/russia/info/ (дата обращения 11.05.2019)

12. Устав Калужской области, утвержден постановлением Законодательного Собрания Калужской области от 27 марта 1996 г. № 473. [Электронный ресурс].

URL: http://www.zskaluga.ru/symbolics/13/podrazdel_2.ht $\mathrm{ml}$ (дата обращения 11.05.2019)

13. Росстат / ТОФС ГС по Калужской области (Калугастат). Смертность населения Калужской области. Статистический сборник. Калуга, 2017: 265.

14. Росстат / ТОФС ГС по Калужской области (Калугастат). Численность и естественное движение населения Калужской области за 2016 г. Статистический сборник. Калуга, 2017: 110.

15. Национальное руководство по суицидологии / Под ред. Б.С. Положего. М.: ООО «Издательство Медицинское информационное агентство», 2019: 600.

16. Чубина С.А., Любов Е.Б., Куликов А.Н. Клинико-эпидемиологический анализ суицидального поведения в Тульской области. Суициидология. 2015; 6, 4: 66-76.

17. Морев М.В., Шматова Ю.Е., Любов Е.Б. Динамика суицидальной смертности населения России: региональный аспект. Суицицология. 2014; 5, (14): 3-11

18. Любов Е.Б., Морев М.В., Фалалеева О.И. Социально-экономическое бремя суицидальной смертности в России. Социальная и клиническая психиатрия. 2013; 23 (2): 38-44.

19. Jeon S.Y., Reither E.N., Masters R.K. A population-based analysis of increasing rates of suicide mortality in Japan and South Korea, 1985-2010. BMC Public Health. 2016 Apr; 16: 356. DOI: 10.1186/s12889-016-3020-2

20. Pampel F.C. Cohort size and age-specific suicide rates: A contingent relationships. Demography. 1996; 3 (33): 341-355.

21. Wray M., Colen C., Pescosolido B. The sociology of suicide. Annual Review of Sociology. 2011; 37(1): 505-528. DOI: 10.1146/annurev-soc081309-150058

22. Любов Е.Б., Магурдумова Л.Г., Цупрун В.Е. Суицидальное поведение пожилых. Суицидология. 2017; 8, 1 (26): 3-16.

23. Бохан Н.А., Стоянова И.Я., Счастный Е.Д., Королёв А.А. Патопсихологические характеристики пациентов с двойным диагнозом в контексте суицидального поведения. Суицидология. 2014; 5, 2 (15): 55-59.

24. Суровцева А.К., Счастный Е.Д. Особенности субъективной оценки качества жизни пациентов с аффективными расстройствами с различным 
риском суицидального поведения. Суицицология. 2014; 5, 4 (17): 52-57.

25. De Beurs D. Network analysis: a novel approach to understand suicidal behavior. International Journal of Environmental Research and Public Health. 2017 Febr; 14(219). DOI: https://doi.org/10.3390/ijerph14030219
26. Cairney J., Streiner D.L., Sakinofsky I., Webster G. The Epidemiology of Suicide in Canada. Mental Disorder in Canada: An Epidemiological Perspective. Toronto: University of Toronto Press, 2010: 464. DOI: https://doi.org/10.3138/9781442698574

Поступила в редакцию 21.10.2019 Утверждена к печати 27.01.2020

Носова Евгения Сергеевна - заведующая отделением ГБУЗ КО «Калужская областная психиатрическая больница им. А.Е. Лифшица». SPIN-код 3224-1027. ORCID ID 0000-0002-8275-7749. Researcher ID W-3801-2017.

Жуков Игорь Вячеславович - главный врач ГБУЗ КО «Калужская областная психиатрическая больница им. A.Е. Лифшица». ORCID ID 0000-0001-7081-6636. Researcher ID AAH-7820-2019. Zhukov_kopb@mail.ru

Радулов Семён Пантелеевич - заместитель главного врача ГБУЗ КО «Калужская областная психиатрическая больница им. А.Е. Лифшица». ORCID ID 0000-0003-2022-9171. Researcher ID AAH-7830-2019. seomara@mail.ru

\section{Носова Евгения Сергеевна, nosova.evgenya@lenta.ru}

UDC 616.89-008.441.44:314.14:341.321.1(470.318)|40|

For citation: Nosova E.S., Zhukov I.V., Radulov S.P. A retrospective analysis of suicide mortality in the Kaluga Region over a 16-year period. Siberian Herald of Psychiatry and Addiction Psychiatry. 2020; 1 (106): 56-66. https://doi.org/10.26617/1810-3111-2020-1(106)-56-66

\section{A retrospective analysis of suicide mortality in the Kaluga Region over a 16-year period}

\section{Nosova E.S., Zhukov I.V., Radulov S.P.}

Kaluga Regional Psychiatric Hospital named after A.E. Lifshitz

Mayakovsky Street 55, 248009, Kaluga, Russian Federation

\section{ABSTRACT}

Studying of suicide mortality is the first step in drawing up a general understanding of the epidemiology of suicide in the region. The analysis of statistical data is aimed at identifying "hot spots" on the map of the region and risk groups for priority interventions. Materials and methods: a retrospective analysis of suicide mortality in the Kaluga Region from 2003 to 2018 is carried out. The indicators are calculated taking into account gender, age differences and place of residence. The trend and long-term prediction using linear regression analysis are determined. Results: for the study period, suicidal mortality in the region as a whole shows a positive trend with a decrease in suicide mortality rates for the period from 2003 to 2018 from 30.14 to 11.67 per $100000\left(R^{2}=0.9206 ; \alpha=0.05\right)$, more pronounced in men (from 54.15 to 20.31 per $100000, \mathrm{R}^{2}=0.9265 ; \alpha=0.05$ ) in comparison with women (from 9.96 to 4.24 per $\left.100000, \mathrm{R}^{2}=0.7177 ; \alpha=0.05\right)$. Using linear regression for all of these groups for the period 2019-2022. a positive prediction is determined to further reduce the levels of suicide mortality. Regression analysis identifies age cohorts with a statistically significant prognosis for a further decrease in suicide mortality for a three-year period: $25-29$, 30$34,50-54$ and 55-59 years old and the working age cohort $\left(\mathrm{R}^{2}=0.6 ; \alpha=0.05\right)$. Conclusions: the risk group is formed at the expense of men of working age and over 65 years old, as well as women over 85 years old. The increase in suicides in the cohort over 85 years old by $45 \%$ of the initial indices in 2003 deserves close attention and further study.

\section{Keywords: suicide mortality, time-series analysis, linear regression, crisis help, the Kaluga Region.}

\section{REFERENCES}

1. World Health Organization [Electronic resource]. URL: $\quad$ https://www.who.int/docs/defaultsource/mental-health/suicide/suicide-flyer-ru.pdf (accessed date 13.10.2019) (in Russian).

2. The General Principles of Suicide Prevention Policy. Realizing a Society in Which No One Is Driven to Take Their Own Life - Cabinet Decision, $25^{\text {th }}$ July 2017. [Electronic resource]. URL: http://www.mindbank.info/item/6766 (accessed date 15.11.2019)

3. World Health Organization [Electronic resource]. URL: https://www.who.int/mental_health/suicideprevention/infographic/ru/ (accessed date 07.12.2019) (in Russian).

4. Federal State Statistics Service of Rosstat [Electronic resource]. URL: https://www.fedstat.ru/indicator/31620 (accessed date 15.12.2019) (in Russian). 
5. Federal State Statistics Service of Rosstat [Electronic resource]. URL: https://www.fedstat.ru/indicator/31270 (accessed date 01.12.2019) (in Russian).

6. Polozhy B.S., Igumnov S.A., Rimer Z. et al. Suitsidy v Rossii i Evrope [Suicides in Russia and Europe]. B.S. Polozhy, ed. Moscow: Medical Information Agency, 2016: 209 (in Russian).

7. Gladyshev M.V. Kliniko-sotsial'nye aspekty rasprostranennosti suitsidov $\mathrm{v}$ period radikal'nykh preobrazovaniy v Rossii (1990-2003 gg.) [Clinicalsocial aspects of the prevalence of suicides during the period of radical transformations in Russia (1990-2003)]: PhD thesis. Moscow, 2006: 169 (in Russian).

8. Federal State Statistics Service of Rosstat [Electronic resource]. URL: https://www.fedstat.ru/indicator/31270 (accessed date 15.12.2019) (in Russian).

9. Rosstat / Territorial authority of the Federal State Statistics Service for the Kaluga Region (Kalugastat). Municipal entities of the Kaluga region in the mirror of demography. Statistical Digest. Kaluga, 2017: 116 (in Russian).

10. Federal State Statistics Service. Federal Agency for Technical Regulation and Metrology. All-Russian classifier of territories of municipalities OK 332013. Volume 1. Central Federal District. Moscow, 2013: 1499 (in Russian).

11. The official portal of the authorities of the Kaluga region [Electronic resource]. URL: https://admoblkaluga.ru/main/russia/info/ (accessed date 11.05.2019) (in Russian).

12. Statute of the Kaluga Region, approved by the decision of the Legislative Assembly of the Kaluga Region dated March 27, 1996 No. 473. [Electronic resource]. URL: http://www.zskaluga.ru/symbolics/13/podrazdel_2.html (accessed date 11.05.2019) (in Russian).

13. Rosstat / Territorial authority of the Federal State Statistics Service for the Kaluga Region (Kalugastat). Mortality of the population of the Kaluga region. Statistical Digest. Kaluga, 2017: 265 (in Russian).

14. Rosstat / Territorial authority of the Federal State Statistics Service for the Kaluga Region (Kalugastat). Number and natural movement of the population of the Kaluga region for 2016. Statistical Digest. Kaluga, 2017: 110 (in Russian).

15. Natsional'noye rukovodstvo po suitsidologii $[\mathrm{Na}-$ tional Guide to Suicidology] / Edited by B.S. Polozhiy. Moscow: Publishing House Medical News Agency, 2019: 600 (in Russian).

16. Chubina S.A., Lyubov E.B., Kulikov A.N. Klinikoepidemiologicheskiy analiz suitsidal'nogo povedeniya v Tul'skoy oblasti [Clinicalepidemiological analysis of suicidal behavior in the Tula region]. Suitsidologiya - Suicidology. 2015; 6, 4: 66-76 (in Russian).
17. Morev M.V., Shmatova Yu.E., Lyubov E.B. Dinamika suitsidal'noy smertnosti naseleniya Rossii: regional'nyy aspekt [Dynamics of suicidal mortality in the Russian population: regional aspect]. Suitsidologiya - Suicidology. 2014; 5, (14): 3-11 (in Russian).

18. Lyubov E.B., Morev M.V., Falaleyeva O.I. Sotsial'no-ekonomicheskoye bremya suitsidal'noy smertnosti v Rossii [Socio-economic burden of suicidal mortality in Russia]. Sotsial'naya $i$ klinicheskaya psikhiatriya - Social and Clinical Psychiatry. 2013; 23 (2): 38-44 (in Russian).

19. Jeon S.Y., Reither E.N., Masters R.K. A population-based analysis of increasing rates of suicide mortality in Japan and South Korea, 1985-2010. BMC Public Health. 2016 Apr; 16: 356. DOI: 10.1186/s12889-016-3020-2

20. Pampel F.C. Cohort size and age-specific suicide rates: A contingent relationships. Demography. 1996; 3 (33): 341-355.

21. Wray M., Colen C., Pescosolido B. The sociology of suicide. Annual Review of Sociology. 2011; 37(1): 505-528. DOI: 10.1146/annurev-soc081309-150058

22. Lyubov E.B., Magurdumova L.G., Tsuprun V.E. Suitsidal'noye povedeniye pozhilykh [Suicidal behavior of the elderly]. Suitsidologiya - Suicidology. 2017; 8, 1 (26): 3-16 (in Russian).

23. Bokhan N.A., Stoyanova I.Ya., Schastnyy E.D., Korolev A.A. Patopsikhologicheskiye kharakteristiki patsiyentov s dvoynym diagnozom $\mathrm{v}$ kontekste suitsidal'nogo povedeniya [Pathopsychological characteristics of patients with a double diagnosis in the context of suicidal behavior]. Suitsidologiya - Suicidology. 2014; 5, 2 (15): 55-59 (in Russian).

24. Surovtseva A.K., Schastnyy E.D. Osobennosti sub"yektivnoy otsenki kachestva zhizni patsiyentov $\mathrm{s}$ affektivnymi rasstroystvami s razlichnym riskom suitsidal'nogo povedeniya [Features of a subjective assessment of the quality of life of patients with affective disorders with different risk of suicidal behavior]. Suitsidologiya - Suicidology. 2014; 5, 4 (17): 52-57 (in Russian).

25. De Beurs D. Network analysis: a novel approach to understand suicidal behavior. International Journal of Environmental Research and Public Health. 2017 Febr; 14(219). DOI: https://doi.org/10.3390/ijerph14030219

26. Cairney J., Streiner D.L., Sakinofsky I., Webster G. The Epidemiology of Suicide in Canada. Mental Disorder in Canada: An Epidemiological Perspective. Toronto: University of Toronto Press, 2010: 464. DOI: https://doi.org/10.3138/9781442698574

Received October 21.2019 Accepted January 27.2020 
Nosova Evgenia S. - Head of the Unit, State Budgetary Healthcare Institution of the Kaluga Region "Kaluga Regional Psychiatric Hospital named after A.E. Lifshitz". SPIN-code 3224-1027. ORCID ID 0000-0002-8275-7749. Researcher ID W-3801-2017.

Zhukov Igor V. - Head Physician, State Budgetary Healthcare Institution of the Kaluga Region "Kaluga Regional Psychiatric Hospital named after A.E. Lifshitz”. ORCID ID 0000-0001-7081-6636. Researcher ID AAH-7820-2019. Zhukov_kopb@mail.ru

Radulov Semen P. - Deputy Head Physician, State Budgetary Healthcare Institution of the Kaluga Region "Kaluga Regional Psychiatric Hospital named after A.E. Lifshitz". ORCID ID 0000-0003-2022-9171. Researcher ID AAH7830-2019. seomara@mail.ru

$\triangle$ Nosova Evgenia S., nosova.evgenya@lenta.ru 